\title{
Occurrence of Aedes cretinus in Cyprus based on information collected by citizen scientists
}

\author{
A.F. Martinou ${ }^{1,2 *}$ iD , J. Fawcett ${ }^{3}$, M. Georgiou ${ }^{1}$, I. Angelidou ${ }^{4}$, M. Philippou ${ }^{1}$ and F. Schaffner ${ }^{5}$ \\ ${ }^{1}$ Joint Services Health Unit, British Forces Cyprus BFPO 57, RAF Akrotiri, Cyprus; ${ }^{2}$ Care-C, Athalassa Campus, 20 \\ Konstantinou Kavafi Street, 2121 Aglantzia, Nicosia, Cyprus; ${ }^{3}$ SO1 EH POL, Army Health, Army Headquarters, IDL 6, \\ Zone 1, Ground Floor, Blenheim Building, Marlborough Lines, Monxton Road, Andover Hants SP11 8HT, S4B, United \\ Kingdom; ${ }^{4}$ Enalia Physis, Acropoleos 2, Aglantzia, 2101, Cyprus; ${ }^{5}$ Francis Schaffner Consultancy, Lörracherstrasse 50, \\ 4125 Riehen, Switzerland; a.martinou@cyi.ac.cy
}

Received: 29 March 2021 / Accepted: 21 September 2021

(c) 2021 A.F. Martinou et al.

RESEARCH ARTICLE

\begin{abstract}
The current study presents a success story where through a small network of citizen scientists original information regarding the occurrence of Aedes cretinus was received, suggesting the absence of invasive Aedes species on the island of Cyprus. Citizen science records show that Ae. cretinus most likely has an island wide spatial distribution while its seasonal activity is limited to the spring and summer months. Data collected by citizen scientists under 'The Three Mosquiteers' citizen science initiative, provided more records than any efforts from the authorities in the last 73 years. The future success and the longevity of this initiative will be strongly dependent on the in-depth engagement and collaboration between local experts in entomology and citizen scientists.
\end{abstract}

Keywords: mosquito surveillance, The Three Mosquiteers project, non-native mosquito, invasive mosquito, Aedes albopictus

\section{Introduction}

Surveillance is an essential component of any integrated mosquito management programme designed for native and non-native mosquitoes in natural, protected areas or urban settings (Martinou et al., 2020; Osorio et al., 2014). Understanding the distribution, abundance and seasonality of mosquitoes at the local scale is necessary for any risk assessment to be possible (Schaffner et al., 2013). Mosquito surveillance is usually undertaken by skilled operators, experts in medical entomology, public health authorities or researchers and it requires a significant amount of expertise and resources in terms of personnel, equipment, and time (ECDC, 2012, 2014; Martinou et al., 2020; Wint et al., 2020).

The public can also contribute towards recording mosquitoes through citizen or community science projects where nonexperts get involved in scientific research (Pataki et al., 2021; Tweddle et al., 2012). Citizen science can enhance and facilitate mosquito surveillance undertaken by authorities at the local level, ensuring better geographic coverage at a finer scale, providing essential information on mosquito diversity, distribution and habitat preferences (Braz-Sousa et al. 2020; Palmer et al., 2017; Pernat et al., 2020; Tyson et al., 2018). Citizen scientists, guided by experts and provided with mosquito identification keys, can contribute to mosquito recording by either collecting mosquito specimens and submitting them to the experts or by using mobile application technologies for photorecordings. The active involvement of citizen scientists can enable data collection, overcoming accessibility or transboundary limitations due to political or financial reasons (Martinou and Roy, 2018; Pernat et al., 2020). Citizen science projects can contribute towards early warning rapid response systems for nonnative mosquitoes informing the authorities and the public (Cardoso et al., 2014).

In Cyprus, so far, there are no records of non-native mosquitoes such as Aedes (Stegomyia) albopictus (Skuse, 1895) (Martinou et al., 2016) and the only record for Aedes 
(Stegomyia) aegypti (Linnaeus, 1762) dates before 1934 (Aziz, 1934). However, horizon scanning exercises predict that both species are likely to arrive and establish on the island (Peyton et al., 2019, 2020). Non-native invasive mosquitoes such as Ae. aegypti or Ae. albopictus have characteristic, recognisable, 'black and white' patterns which allow a preliminary identification by citizen scientists and subsequent validation by experts. In Cyprus and parts of the Mediterranean region there is also one native species Aedes (Stegomyia) cretinus Edwards 1921 that strongly resembles Ae. albopictus (Martinou et al., 2016; Robert et al., 2019). Both Ae. cretinus and Ae. albopictus have a median longitudinal stripe on their scutum (thorax) and two sub-median narrow lines. However, Ae. albopictus harbours short sub-median lines while Ae. cretinus shows longer lines that extend forward to the scutum (Gunay et al., 2018). Apart from this difference the two species are morphologically identical. Ae. cretinus has been found in mainland Greece and the island of Crete, Cyprus, Georgia and Turkey (Alten et al., 2000; Edwards, 1921; Giatropoulos et al., 2012; Lane, 1982; Martinou et al., 2016; Samanidou, 1998). In Cyprus, the species was first recorded in 1949 in Nicosia (Lane, 1982) but it was not listed among the mosquito species for Cyprus (Hadjivassilis, 2000; Violaris et al., 2009). Since then, it was reported, 66 years later, in 2015 by Martinou et al. (2016).

A long-term surveillance scheme for native or non-native mosquitoes is still lacking for the largest part of the island of Cyprus as well as for potential points of entry for non-native species such as ports, airports and marinas. Any monitoring is not island wide and relies on short term efforts, except for the UK Sovereign Base Areas where there is a long-term surveillance scheme that covers the RAF airport and the Limassol port (Martinou and Roy, 2018).

The current study aims at presenting a new approach as to mosquito monitoring in Cyprus, through citizen science. Targeting the native Ae. cretinus that strongly resembles the non-native Ae. albopictus, will increase awareness regarding non-native mosquitoes. It could help towards the timely detection and recording of non-native mosquitoes before they manage to establish. Herein, we present the first results collected through a small network of citizen scientists with original information on the occurrence of Ae. cretinus which is also suggesting the absence of invasive non-native Aedes species on the island of Cyprus.

\section{Materials and methods}

In 2015, the Joint Services Health Unit (JSHU), British Forces Cyprus, raised two questions: (1) whether Aedes invasive non-native mosquitoes were present on the island of Cyprus; as there was no island wide surveillance programme undertaken by the authorities, it was impossible to know; (2) whether citizens could help the authorities find out what is the case for invasive non-native mosquitoes by trying to detect non-native mosquitoes and by providing mosquito occurrence records. JSHU initiated a campaign about invasive non-native mosquitoes such as Ae. albopictus and Ae. aegypti so that citizens would be able to detect, identify and record them if they were introduced on the island.

In order to help the campaign and find citizens who were willing to share information, short films, newspaper articles and informative educational material (https://alien-csi.eu/ dissemination-materials) were produced, addressed both to adults, and children. Scientific workshops and science fairs took place through 'The Three Mosquiteers' pilot project (https://scistarter.org/the-three-mosquiteers; Tyson et al., 2018). Social media and questionnaire-based surveys were also employed through which citizens were asked to report mosquito nuisance and whether they have seen 'black and white' mosquitoes.

Citizens were informed about the native mosquito $A e$. cretinus through social networks or during presentations and received entomological keys and photographs for all three species: the native Ae. cretinus and two non-native species, Ae. albopictus and Ae. aegypti (ECDC, 2012; Gunay et al., 2018). An example of an Ae. cretinus specimen used can be viewed in Figure 1. The citizens were given detailed guidance regarding what should be included in the submitted records, for example good photorecordings of the scutum are essential to be able to distinguish Ae. cretinus from Ae. albopictus.

Informed citizens started collecting records and either share photorecordings for 'black and white' mosquitoes via email or the social media (https://www.facebook.com/

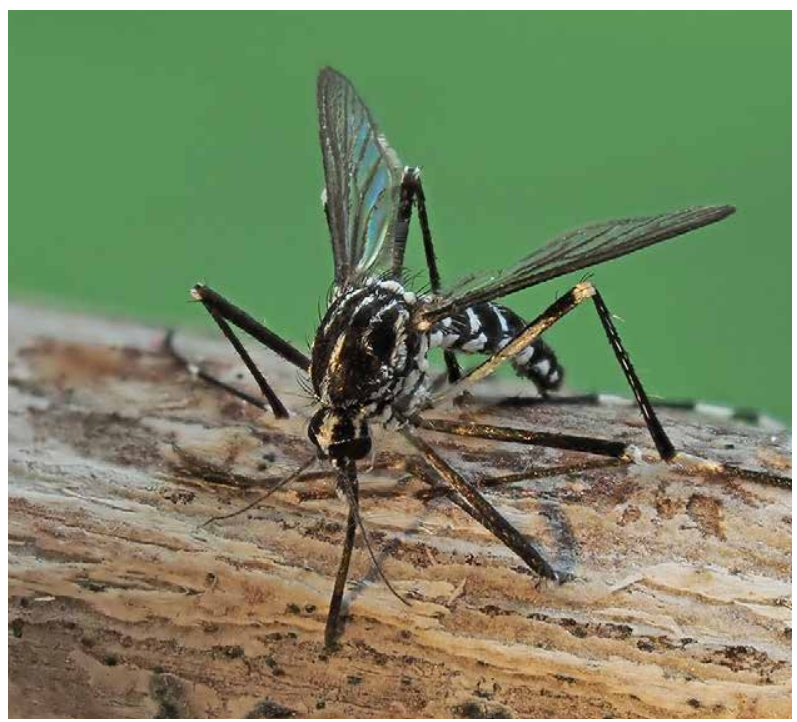

Figure 1. A photo of an Aedes cretinus female that was used to inform the citizen scientists via social media about this native species (photo credit: Marios Philippou, JSHU). 
thethreemosquiteers) or sent specimens to the Laboratory of Vector Ecology and Applied Entomology, JSHU for expert identification by one or more medical entomologists. Once the experts identified the records, they provided feedback to the citizen scientists either via email or the social media. Targeted visits were also organised by JSHU experts at locations where citizen scientists reported nuisance due to 'black and white' mosquitoes.

\section{Results}

The first two records (mosquito specimens) for 'black and white' mosquitoes from citizen scientists arrived in June 2015 from Agia Mavri, Koilani, Limassol region and from Avdellero, Larnaca region (Martinou et al., 2016). Island wide efforts to inform the public were intensified in the following years and started being more fruitful in spring 2018 when photorecordings of 'black and white' mosquitoes made by citizen scientists were received via social media or email.

Between 2018 and 2020 a total of thirty-nine records of 'black and white' mosquitoes were received. None of the records included non-native mosquitoes such as $A e$. albopictus. All the records were made during the spring and summer months which leads us to believe that Ae. cretinus has a seasonal distribution, unlike other mosquito species present on the island e.g. the common house mosquito (Culex pipiens s.l.) or the salt marsh mosquito (Ae. detritus). Depending on rainfall, the latter are present all year long (Martinou, unpublished data). Twenty of the submitted records were photorecordings or specimens of Ae. cretinus submitted by citizens scientists that were validated by experts (Figure 2).

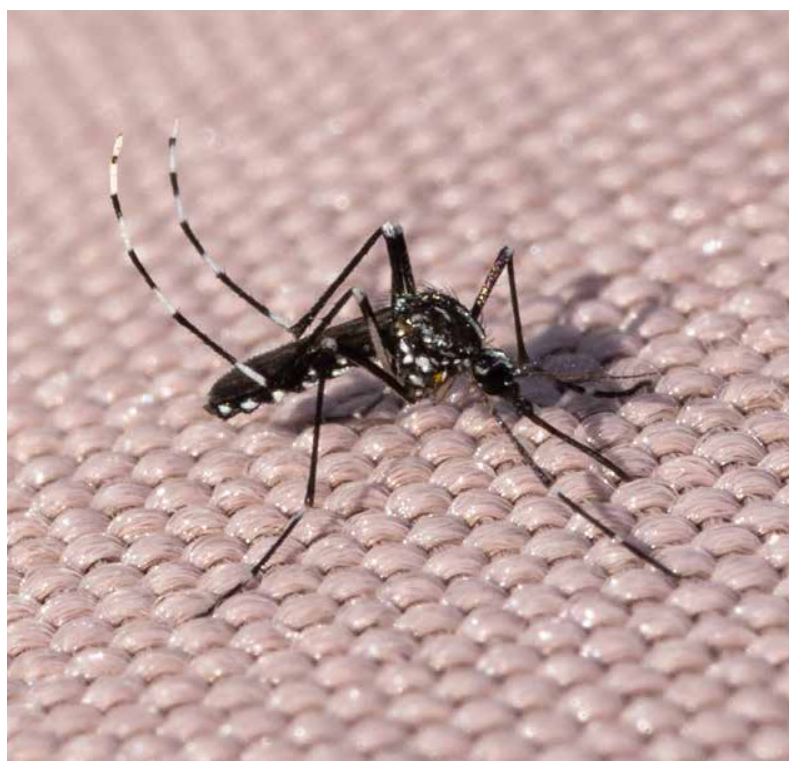

Figure 2. A photorecording by one of our citizen scientists taken in Tala, Paphos 06/06/2020 (photo credit: Dave Walker).
Specimen collections were also made by a team of experts during onsite visits based on nuisance reports due to 'black and white' mosquitoes provided by citizen scientists. Verification was undertaken by one or more entomologists who examined the photorecordings or the specimens morphologically. Five records remained unverified as the citizen scientists were unable to photograph or collect the specimens. These unverified records are also included in Figure 3 and Table 1 as the citizen scientists who provided the information were experienced in identifying or collecting Ae. cretinus.

Another five records (habitat) were considered as suitable habitats for Ae. cretinus (as nuisance reports were provided for these locations) even though no Ae. cretinus specimens were collected at the time of the onsite visits by the experts (Figure 3; Table 1).

The previous three records presented by Martinou et al. (2016) are also included on Figure 3 (older records). There was only one record of another native mosquito species collected by a citizen scientist, which was a specimen of Culiseta longiareolata collected in Pareklissia, Limassol, on the $26^{\text {th }}$ of April 2020. During the onsite visits, the other mosquito species collected were Culex hortensis, Anopheles claviger and $\mathrm{Cu}$. longiareolata (Table 2), while other encountered species were larvae of the Chironomidae family and copepods such as Megacyclops spp.

\section{Discussion}

Aedes cretinus was difficult to be located by public health authorities due to the lack of an island wide mosquito surveillance scheme and the species' habitat preferences i.e. a dendrolimnic species breeding in tree holes (Gutsevich et al., 1974; Martinou and Roy, 2018). Public engagement proved very important on this occasion in contributing knowledge for a rarely collected and poorly documented mosquito species for Cyprus and the wider Mediterranean region. The records presented herein show that Ae. cretinus, most likely has an island wide distribution, that it is present at a wide range of altitudes and it has a strong preference for habitats with shaded streams and deciduous vegetation (Figure 4).

Understanding the current distribution of Ae. cretinus is important as it is an aggressive anthropophilic daytime biter (Darsie, 1999; Samanidou-Voyadjoglou and Koliopoulos, 1998) and it can cause a great amount of nuisance at the locations where it is present. Furthermore, it belongs to the subgenus Stegomyia which contains many vector species such as Ae. albopictus and Ae. aegypti. Collecting occurrence data and mapping its spatiotemporal distribution could also be indicative of the areas with most nuisance for local residents and tourists. Our study also shows that Ae. cretinus is associated with An. claviger, an historical 


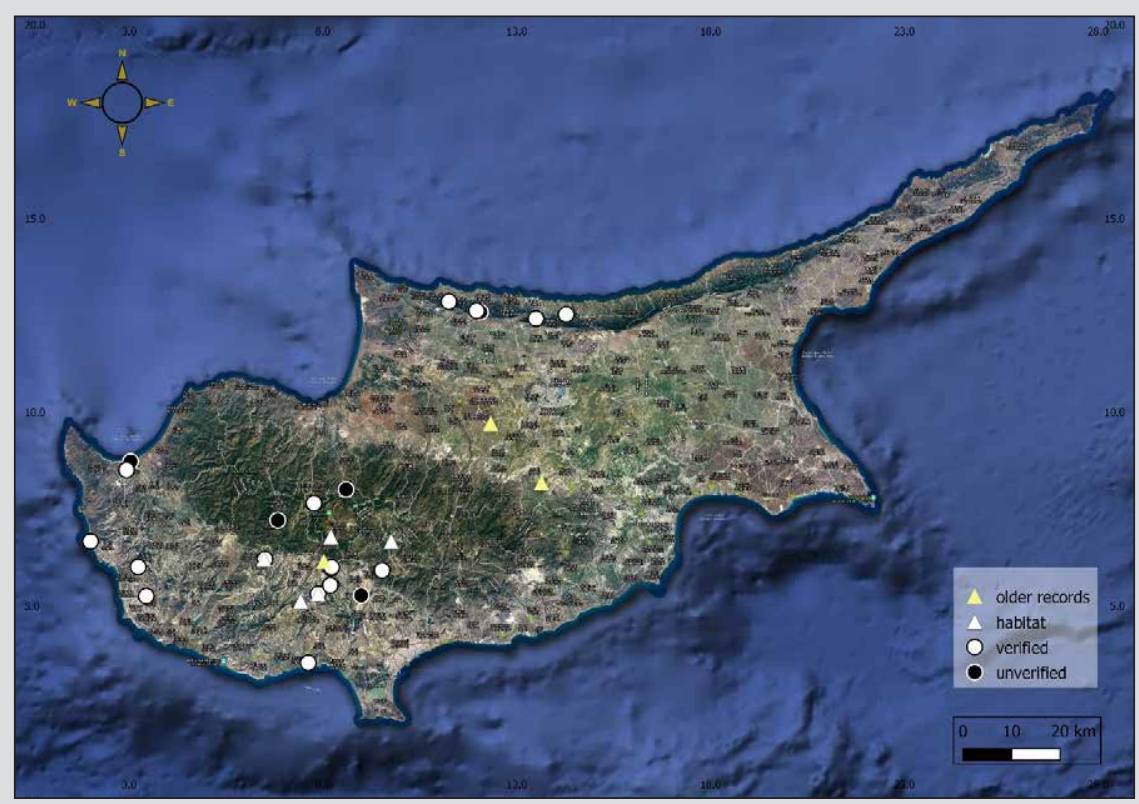

Figure 3. Records of Aedes cretinus based on information provided by citizen scientists. Verified records are those that experts checked specimens or photorecordings. Unverified records are observations made by experienced citizen scientists who were unable to collect the mosquito specimen. Habitat stands for areas that were characterised as suitable for Ae. cretinus during the onsite visits by the experts. Older records date before 2018 (Martinou et al., 2016).

malaria vector in the Eastern Mediterranean region, it will be good to investigate further any interactions of $A e$. cretinus with other mosquito species (Becker et al., 2010). More studies are needed as currently very little is known about the biology of Ae. cretinus (Becker et al., 2010; Lane, 1982 ) and its vector potential remains unknown (Martinou et al., 2016; Schaffner and Mathis, 2014).

The last few years citizen science projects have become important for monitoring vector-borne diseases and the surveillance of species of medical importance such as mosquitoes (Ashepet et al., 2020; Bartumeus et al., 2018; Braz-Sousa et al., 2020; Pernat, 2020; Tyson et al., 2018; Walther and Kampen, 2017), kissing bugs (Triatominae) (Curtis-Robles et al., 2015) and ticks (Porter et al., 2019). Citizen science efforts can complement the work undertaken by public health authorities in order to predict or manage the risk of vector-borne diseases. During the 'Mückenatlas' project, a citizen science initiative for recording mosquitoes in Germany, it was shown that mosquito monitoring by citizen scientists better detected invasive species by collecting information regarding mosquitoes from private premises that professionals usually could not access (Pernat et al., 2020).

Unlike its counterparts, Mückenatlas and Mosquito Alert (in Germany and Spain, respectively) The Three Mosquiteers is still a small network at an embryonic pilot stage. However, even though the size of the network is small, the occurrence data are very valuable as prior to the network Ae. cretinus had only been recorded three times in 73 years on the island. Current occurrence data help us understand better the spatiotemporal distribution of Ae. cretinus in Cyprus. One of the advantages of the small size of the network is that it enables good communication and feedback between citizen scientists and professional entomologists which will hopefully set the foundations for a strong vector citizen science community on island.

Citizen science projects can last far longer than any individual effort and cover far more ground. Therefore, they are particularly effective in mapping the spatial distributions of species, their declines or increases given that the target species can be easily identified (Adler et al., 2020). Citizen science records can inform us about key dispersal mechanisms, changes in species distribution as a result of climate change, the spread of biological invasions at scales not attainable through more traditional methods and for tracking infectious disease at different spatial and temporal scales (Adler et al., 2020; Groom et al., 2019). Even when citizen science studies are not maintained continuously over long periods of time, linking studies to historical amateur naturalist datasets can offer valuable information, enable comparisons and create studies that encompass decades or centuries worth of data (Science Communication Unit, 2013). These historical data provide a foundation for assessing species richness and occurrence across a landscape and for measuring the conservation status of rare and elusive species (Adler et al., 2020). Citizen science on islands like Cyprus, without a long 
Table 1. Aedes cretinus records collected by citizen scientists (CS) or the Joint Services Health Unit team of experts (JSHU) after receiving reports regarding nuisance by 'black and white' mosquitoes.

\begin{tabular}{|c|c|c|c|c|c|c|c|}
\hline Date & District & Grid north & Grid east & Altitude (m) & Recorder & Ae. cretinus & Record \\
\hline 18/06/2018 & Paphos & 35.04116 & 32.41833 & 0 & CS1 & 1 우 & unverified \\
\hline $30 / 06 / 2020$ & Nicosia & 34.93316 & 32.74857 & 620 & CS1 & 1 우 & unverified \\
\hline $01 / 05 / 2018$ & Kyrenia & 35.31521 & 33.20263 & 268 & CS10 & 19 & unverified \\
\hline 05/05/2020 & Paphos & 34.89431 & 32.32858 & 200 & CS11 & 1 우 & verified \\
\hline $06 / 05 / 2020$ & Paphos & 34.89431 & 32.32858 & 200 & CS11 & 19 & verified \\
\hline $21 / 06 / 2020$ & Nicosia & 34.96443 & 32.82964 & 1,100 & CS12 & 1 우 & verified \\
\hline 19/07/2020 & Limassol & 34.81337 & 32.86643 & 800 & CS13 & 1 우 & verified \\
\hline 23/09/2018 & Paphos & 34.86144 & 32.71989 & 615 & CS2 & 19 & verified \\
\hline $14 / 05 / 2019$ & Kyrenia & 35.30333 & 33.32758 & 220 & $\operatorname{cs} 3$ & 1 우 & verified \\
\hline $14 / 05 / 2019$ & Kyrenia & 35.31087 & 33.39529 & 954 & CS3 & 19 & verified \\
\hline $11 / 07 / 2020$ & Nicosia & 34.98952 & 32.90166 & 700 & CS3 & 1 우 & unverified \\
\hline 20/06/2019 & Paphos & 34.84704 & 32.43548 & 500 & CS4 & $3 q$ & verified \\
\hline 06/06/2020 & Paphos & 34.84704 & 32.43548 & 500 & CS4 & 1 우 & verified \\
\hline 20/06/2019 & Paphos & 34.79353 & 32.45357 & 0 & CS5 & 1 우 & verified \\
\hline $30 / 06 / 2019$ & Limassol & 34.79491 & 32.93551 & 550 & cs6 & 1 우 & unverified \\
\hline $03 / 05 / 2020$ & Kyrenia & 35.33442 & 33.13234 & 0 & CS7 & 1 우 & verified \\
\hline $03 / 05 / 2020$ & Paphos & 35.02552 & 32.40936 & 40 & CS8 & 1 우 & verified \\
\hline $03 / 05 / 2020$ & Kyrenia & 35.31778 & 33.19434 & 663 & cs9 & 1 우 & verified \\
\hline $05 / 05 / 2020$ & Kyrenia & 35.31778 & 33.19434 & 12 & $\operatorname{cs} 9$ & 1 우 & verified \\
\hline $19 / 06 / 2018$ & Limassol & 34.50401 & 32.5208 & 900 & JSHU & 23 ? & verified \\
\hline $20 / 06 / 2018$ & Limassol & 34.84083 & 32.98237 & 240 & JSHU & 29 & verified \\
\hline $20 / 06 / 2018$ & Limassol & 34.89471 & 33.00304 & 820 & JSHU & 0 & habitat suitability \\
\hline $27 / 06 / 2018$ & Limassol & 34.50401 & 32.5208 & 900 & JSHU & $35 \% ; 10^{\hat{n}}$ & verified \\
\hline $27 / 06 / 2018$ & Limassol & 34.79752 & 32.83887 & 640 & JSHU & 0 & verified \\
\hline 09/07/2018 & Limassol & 34.50401 & 32.5208 & 900 & JSHU & $2+$ & verified \\
\hline 09/07/2018 & Limassol & 34.86173 & 32.71777 & 1,200 & JSHU & 0 & none \\
\hline $24 / 04 / 2019$ & Episkopi & 34.67094 & 32.81695 & 0 & JSHU & 1 우 & verified \\
\hline 20/05/2019 & Limassol & 34.50401 & 32.5208 & 900 & JSHU & 1 우 & verified \\
\hline 20/05/2019 & Limassol & 34.51337 & 32.5229 & 900 & JSHU & 1 우 & verified \\
\hline $20 / 05 / 2019$ & Limassol & 34.51337 & 32.5229 & 900 & JSHU & 1 우 & verified \\
\hline 20/05/2019 & Limassol & 34.50401 & 32.5208 & 900 & JSHU & 1 우 & verified \\
\hline $20 / 05 / 2019$ & Limassol & 34.78391 & 32.7998 & 640 & JSHU & 0 & habitat suitability \\
\hline 20/05/2019 & Limassol & 34.90297 & 32.8677 & 1,330 & JSHU & 0 & habitat suitability \\
\hline $30 / 06 / 2019$ & Limassol & 34.51337 & 32.5229 & 900 & JSHU & 30 & verified \\
\hline 08/07/2019 & Limassol & 34.51337 & 32.5229 & 900 & JSHU & 10 우 & verified \\
\hline 29/07/2019 & Limassol & 34.51337 & 32.5229 & 900 & JSHU & 0 & habitat suitability \\
\hline $15 / 06 / 2020$ & Limassol & 34.51337 & 32.5229 & 900 & JSHU & 30 & verified \\
\hline 07/07/2020 & Limassol & 34.51337 & 32.5229 & 900 & JSHU & 1 오 & verified \\
\hline
\end{tabular}

Table 2. Aedes cretinus and other species collected during the on-site visits.

\begin{tabular}{|c|c|c|c|c|c|c|}
\hline Date & District & Grid north & Grid east & Ae. cretinus o & Other mosquito species & Other species \\
\hline $27 / 06 / 2018$ & Limassol & 34.50400 & 32.52080 & $35 \% ; 10^{\lambda}$ & Culiseta longiareolata & Chironomus spp.; Megacyclops spp \\
\hline 09/07/2018 & Limassol & 34.50400 & 32.52080 & 29 & Anopheles claviger & \\
\hline $20 / 05 / 2019$ & Limassol & 34.50400 & 32.52080 & 10 & An. claviger & \\
\hline $20 / 05 / 2019$ & Limassol & 34.51337 & 32.52290 & 1 우 & An. claviger & \\
\hline 20/05/2019 & Limassol & 34.51337 & 32.52290 & 1 우 & Cu. longiareolata & Chironomus spp.; Megacyclops spp \\
\hline $20 / 05 / 2019$ & Limassol & 34.50400 & 32.52080 & 1 우 & Culex hortensis & \\
\hline
\end{tabular}




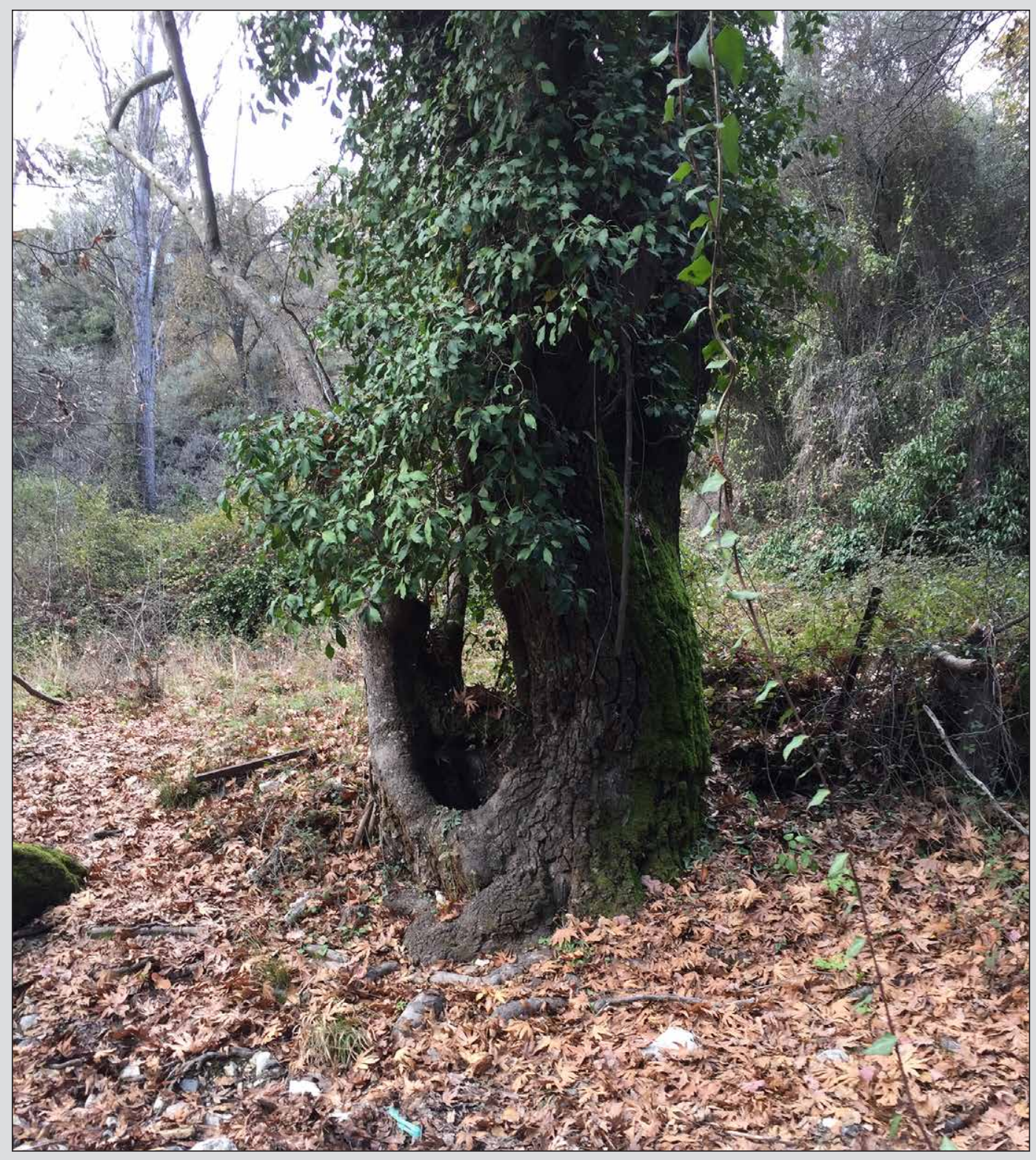

Figure 4. Typical habitat of Aedes cretinus in the Limassol District (photo credit: A.F. Martinou, JSHU).

tradition in recording schemes can be challenging, even more so when the project focuses on nuisance species or vectors of disease. For such a citizen science initiative to be successful, continuous communication and exchange of information is required between the experts and the citizen scientists who participate. In the future we hope to attract more citizen scientists towards The Three Mosquiteers initiative by also promoting and adopting the European Mosquito Alert app that was recently released in many European languages through the AIM-COST network (www.aedescost.eu). As we hope to expand The Three Mosquiteers network, adopting an app such as Mosquito Alert will offer advantages by providing island wide coverage at finer scales and by providing feedback to the citizen scientists in a timely manner. Extra effort should be placed from the experts and the authorities into turning the information collected by The Three Mosquiteers network into management actions for the verified records of mosquito presence and nuisance, as this is expected by the citizen scientists (Ashepet et al., 2020). Training of public health workers island wide on surveillance techniques such as larval dipping in tree holes in order to monitor for Ae. cretinus and treating or managing tree holes where citizen scientists indicate that Ae. cretinus breeds or causes nuisance should be considered. The longevity of The Three Mosquiteers network, the quality of information and its success will be strongly dependent on the deep engagement between experts and citizen scientists. 


\section{Acknowledgements}

We are grateful to all the citizen scientists who participated and contributed information to The Three Mosquiteers project. We would like to thank COST Action CA17122, Alien CSI and the Darwin Plus project DP088 for funding the creation of The Three Mosquiteers leaflet for our young citizen scientists https://alien-csi.eu/disseminationmaterials. This article is based upon work from COST Action Aedes Invasive Mosquitoes, supported by the European Cooperation in Science and Technology (COST) www.cost.eu.

\section{Conflict of interest}

The authors declare no conflict of interest.

\section{References}

Adler, F.R., Green, A.M. and Şekercioğlu, Ç.H., 2020. Citizen science in ecology: a place for humans in nature. Annals of the New York Academy of Sciences 1469: 52-64. https://doi.org/10.1111/ nyas. 14340

Alten, B., Çaglar S.S. and Özer, N., 2000. Malaria and its vectors in Turkey. Journal of the European Mosquito Control Association 7: 27-33.

Ashepet, M.G., Jacobs, L., Van Oudheusden, M. and Huyse, T., 2020. Wicked solution for wicked problems: citizen science for vectorborne disease control in Africa. Trends in Parasitology 37(2): 93-96. https://doi.org/10.1016/j.pt.2020.10.004

Aziz, M., 1934. The Anopheline mosquitoes of Cyprus. Cyprus Government Printing Office, Nicosia, Republic of Cyprus, 26 pp.

Bartumeus, F., Oltra, A. and Palmer, J.R.B., 2018. Citizen science: a gateway for innovation in disease-carrying mosquito management? Trends in Parasitology 34(9): 727-729. https://doi.org/10.1016/j. pt.2018.04.010

Becker, N., Petrić, D., Zgomba, M., Boase, C., Madon, M., Dahl, C. and Kaiser, A., 2010. Mosquitoes and their control, $2^{\text {nd }}$ edition. Springer Verlag, Berlin Heidelberg, Germany, 577 pp.

Braz Sousa, L., Fricker, S.R., Doherty, S.S., Webb, C.E., Baldock, K.L. and Williams, C.R., 2020. Citizen science and smartphone e-entomology enables low-cost upscaling of mosquito surveillance. Science of the Total Environment 704: 135349. https://doi. org/10.1016/j.scitotenv.2019.135349

Cardoso, A., Katsanevakis, S., D`amico, F., Deriu, I.A., 2014. European early warning and rapid response system of invasive alien species. In: $8^{\text {th }}$ International Conference on Biological Invasions: from understanding to action. XMAT, Antalya, Turkey, pp. 68.

Curtis-Robles, R., Wozniak, E.J., Auckland, L.D., Hamer, G.L. and Hamer, S.A., 2015. Combining public health education and disease ecology research: using citizen science to assess Chagas disease entomological risk in Texas. PLoS Neglected Tropical Diseases 9(12): e0004235. https://doi.org/10.1371/journal.pntd.0004235
Darsie Jr, R.F., 1999. Description of the pupa of Aedes cretinus Edwards, a key to the pupae of the Albopictus subgroup, subgenus Stegomyia Theobald, genus Aedes Meigen, and characters to separate the European Stegomyia species (Diptera: Culicidae). Proceedings of the Entomological Society of Washington 101: 614-618.

Edwards, F.W., 1921. A revision of the mosquitoes of the Palaearctic region. Bulletin of Entomological Research 12: 263-351. https:// doi.org/10.1017/S0007485300040207

European Centre for Disease Prevention and Control (ECDC), 2012. Guidelines for the surveillance of invasive mosquitoes in Europe. ECDC, Stockholm, Sweden.

European Centre for Disease Prevention and Control (ECDC), 2014. Guidelines for the surveillance of native mosquitoes in Europe. ECDC, Stockholm, Sweden.

Giatropoulos, A.K., Michaelakis, A.N., Koliopoulos, G.Th. and Pontikakos, C.M., 2012. Records of Aedes albopictus and Aedes cretinus (Diptera: Culicidae) in Greece from 2009 to 2011. Hellenic Plant Protection Journal 5: 49-56.

Groom, Q., Strubbe, D., Adriaens, T., Davis, A.J.S., Desmet, P., Oldoni, D., Reyserhove, L., Roy, H.E. and Vanderhoeven, S., 2019. Empowering citizens to inform decision-making as a way forward to support invasive alien species policy. Citizen Science: Theory and Practice 4(1): 33.

Gunay, F., Picard, M. and Robert, V., 2018. MosKeyTool, an interactive identification key for mosquitoes of Euro-Mediterranean. Version 2.1. Available at: http://medilabsecure.com/moskeytool

Gutsevich, A.V., Monchadskii, A.S.N. and Shtakelberg, A.A., 1974. Mosquitoes, Family Culicidae. Fauna of the USSR, Diptera. Vol. 3. Keter Publishing House Jerusalem Ltd, Jerusalem, Israel, 408 pp.

Hadjivassilis, A., 2000. Mosquitoes (Diptera, Culicidae) of Cyprus. European Mosquito Bulletin 7: 38.

Lane J., 1982. Aedes (Stegomyia) cretinus Edwards 1921 (Diptera: Culicidae). Mosquito Systematics 14(2): 81-85.

Martinou, A.F. and Roy, H.E., 2018. From local strategy to global frameworks: effects of invasive non-native species on health and well-being. In: Mazza, G. and Tricarico, E. (eds.) Invasive species and human health. CABI Publishing, Wallingford, UK, pp. 11-22.

Martinou, A.F., Schäfer, S.M., Bueno Mari, R., Angelidou, I., Erguler, K., Fawcett, J., Ferraguti, M., Foussadier, R., Gkotsi, T.V., Martinos, C.F., Schäfer, M., Schaffner, F., Peyton, J.M., Purse, B.V., Wright, D.J. and Roy, H.E., 2020. A call to arms: setting the framework for a code of practice for mosquito management in European wetlands. Journal of Applied Ecology 57(6): 1012-1019. https://doi.org/10.1111/13652664.13631

Martinou, A.F., Vaux, A.G.C., Bullivant, G., Charilaou, P., Hadjistyllis, H., Shawcross, K., Violaris, M. and Medlock, J., 2016. Rediscovery of Aedes cretinus (Edwards, 1921) (Diptera; Culicidae) in Cyprus, 66 years after the first and unique report. Journal of the European Mosquito Control Association 34: 10-13.

Osório, H.C., Zé-Zé, L., Amaro, F. and Alves, M.J., 2014. Mosquito surveillance for prevention and control of emerging mosquitoborne diseases in Portugal - 2008-2014. International Journal of Environmental Research and Public Health 11(11): 11583-11596. https://doi.org/10.3390/ijerph111111583 
Palmer, J.R.B., Oltra, A., Collantes, F., Delgado, J.A., Lucientes, J., Delacour, S., Bengoa, M., Eritja, R. and Bartumeus, F., 2017. Citizen science provides a reliable and scalable tool to track diseasecarrying mosquitoes. Nature Communications 8: 916. https://doi. org/10.1038/s41467-017-00914-9

Pataki, B.A., Garriga, J., Eritja, R. Palmer, J.R.B., Bartumeus, F. and Csabai, I., 2021. Deep learning identification for citizen science surveillance of tiger mosquitoes. Scientific Reports 11: 4718. https:// doi.org/10.1038/s41598-021-83657-4

Pernat, N., Kampen, H., Jeschke, J.M. and Werner, D., 2020. Citizen science versus professional data collection: comparison of approaches to mosquito monitoring in Germany. Journal of Applied Ecology 58(2): 214-223. https://doi.org/10.1111/1365-2664.13767

Peyton, J., Martinou, A.F., Pescott, O.L., Demetriou, M., Adriaens, T., Arianoutsou, M., Bazos, I., Bean, C.W., Booy, O., Botham, M., Britton, J.R., Cervia, J.L., Charilaou, P., Chartosia, N., Dean, H.J., Delipetrou, P., Dimitriou, A.C., Dörflinger, G., Fawcett, J., Fyttis, G., Galanidis, A., Galil, B., Hadjikyriakou, T., Hadjistylli, M., Ieronymidou, C., Jimenez, C., Karachle, P., Kassinis, N., Kerametsidis, G., Kirschel, A.N.G., Kleitou, P., Kleitou, D., Manolaki, P., Michailidis, N., Mountford, J.O., Nikolaou, C., Papatheodoulou, A., Payiatas, G., Ribeiro, F., Rorke, S.L., Samuel, Y., Savvides, P., Schafer, S.M., Tarkan, A.S., Silva-Rocha, I., Top, N., Tricarico, E., Turvey, K., Tziortzis, I., Tzirkalli, E., Verreycken, H., Winfield, I.J., Zenetos, A. and Roy, H.E., 2019. Horizon scanning for invasive alien species with the potential to threaten biodiversity and human health on a Mediterranean island. Biological Invasions 21: 2107-2125.

Peyton, J.M., Martinou, A.F., Adriaens, T., Chartosia, N., Karachle, P.K., Rabitsch, W., Tricarico, E., Arianoutsou, M., Bacher, S., Bazos, I., Brundu, G., Bruno-McClung, E., Charalambidou, I., Demetriou, M., Galanidi, M., Galil, B., Guillem, R., Hadjiafxentis, K., Hadjioannou, L., Hadjistylli, M., Hall-Spencer, J.M., Jimenez, C., Johnstone, G., Kleitou, P., Kletou, D., Koukkoularidou, D., Leontiou, S., Maczey, N., Michailidis, N., Mountford, J.O., Papatheodoulou, A., Pescott, O.L., Phanis, C., Preda, C., Rorke, S., Shaw, R., Solarz, W., Taylor, C.D., Trajanovski, S., Tziortzis, I, Tzirkalli, E., Uludag, A., Vimercati, G., Zdraveski, K., Zenetos, A. and Roy, H.E., 2020. Horizon scanning to predict and prioritize invasive alien species with the potential to threaten human health and economies on Cyprus. Frontiers Ecology and Evolution 8: 566281. https://doi.org/10.3389/fevo.2020.566281

Porter, W.T., Motyka, P.J., Wachara, J., Barrand, Z.A., Hmood, Z., McLaughlin, M., Pemberton, K. and Nieto, N.C., 2019. Citizen science informs human-tick exposure in the Northeastern United States. International Journal of Health Geographics 18: 9. https:// doi.org/10.1186/s12942-019-0173-0
Robert, V., Günay, F., Le Goff, G., Boussès, P., Sulesco, T., Khalin, A., Medlock, J., Kampen, H., Petrić, D. and Schaffner, F., 2019. Distribution chart for Euro-Mediterranean mosquitoes (western Palaearctic region). Journal of the European Mosquito Control Association 37: 1-28.

Samanidou, A., 1998. Aedes cretinus: is it a threat to the Mediterranean Countries? European Mosquito Bulletin 1: 8.

Samanidou-Voyadjoglou, A. and Koliopoulos, G., 1998. Some notes on Aedes (Stegomyia) cretinus Edwards (Culicidae) in northern Athens, Attiki, Greece. In: Fourth International Congress of Dipterology. 6-13 September. Oxford, UK, pp. 194-195.

Schaffner, F. and Mathis, A., 2014. Dengue and dengue vectors in the WHO European region: past, present, and scenarios for the future. Lancet Infectious Diseases 14(12): 1271-1280. https://doi. org/10.1016/s1473-3099(14)70834-5

Schaffner, F., Bellini, R., Petrić, D. Scholte, E.J., Zeller, H. and Rakotoarivony, L.M., 2013. Development of guidelines for the surveillance of invasive mosquitoes in Europe. Parasites Vectors 6: 209.

Science Communication Unit, 2013. Science for environment policy in depth report: environmental citizen science. Report produced for the European Commission DG Environment. Science Communication Unit, University of the West of England, Bristol, UK.

Tweddle, J.C., Robinson, L.D., Pocock, M.J.O. and Roy, H.E., 2012. Guide to citizen science: developing, implementing and evaluating citizen science to study biodiversity and the environment in the UK. Natural History Museum and NERC Centre for Ecology \& Hydrology for UK-EOF. Available at: https://www.ceh.ac.uk/sites/ default/files/citizenscienceguide.pdf

Tyson, E., Bowser, A., Palmer, J., Kapan, D., Bartumeus, F., Brocklehurst, M. and Pauwels, E., 2018. Global Mosquito Alert: building citizen science capacity for surveillance and control of disease-vector mosquitoes. Workshop Report Volume 2. Woodrow Wilson International Center for Scholars, Washington, DC, USA.

Violaris, M., Vasquez, M.I., Samanidou, A., Wirth, M.C. and Hadjivassilis, A., 2009. The mosquito fauna of the Republic of Cyprus: a revised list. Journal of the American Mosquito Control Association 25(2): 199-202. https://doi.org/10.2987/08-5793.1

Walther, D. and Kampen, H., 2017. The citizen science project 'Mueckenatlas' helps monitor the distribution and spread of invasive mosquito species in Germany. Journal of Medical Entomology 54(6): 1790-1794. https://doi.org/10.1093/jme/tjx166

Wint, W., Petrić, D., Caputo, B., Erguler, K., Gunay, F., Karvan, M., Manica, M., Martinou, A.F., Michaelakis, A., Miranda, M., Salasan, C., Schaffner, F., Veronesi, E. and Della Torre A., 2020. A questionnaire-based survey of surveillance and integrated management of Aedes invasive mosquito in Europe. Technical Report. AIM-COST Action CA 17108. University La Sapienza, Rome, Italy. 